\title{
Cellulose Stabilized Polyvinyl Acetate Emulsion: Review
}

\author{
Pritam V. Dhawale, S. K. Vineeth, Ravindra V. Gadhave*, Prakash A. Mahanwar \\ Department of Polymer and Surface Engineering, Institute of Chemical Technology, Mumbai, India \\ Email: pritamdhawale28@gmail.com, vineetheskay@gmail.com, ${ }^{\star}$ ravi.gadhave3@gmail.com, pa.mahanwar@ictmumbai.edu.in
}

How to cite this paper: Dhawale, P.V., Vineeth, S.K., Gadhave, R.V. and Mahanwar, P.A. (2021) Cellulose Stabilized Polyvinyl Acetate Emulsion: Review. Open Journal of Organic Polymer Materials, 11, 51-66. https://doi.org/10.4236/ojopm.2021.112002

Received: November 21, 2019

Accepted: April 25, 2021

Published: April 28, 2021

Copyright (อ 2021 by author(s) and Scientific Research Publishing Inc. This work is licensed under the Creative Commons Attribution International License (CC BY 4.0).

http://creativecommons.org/licenses/by/4.0/ (c) (i) Open Access

\begin{abstract}
The global energy crisis and overconsumption of non-renewable resources have depleted natural resources, climatic changes with global warming, and rise in sea level. The research on alternate sources and chemicals has resulted in the usage of green materials. These biomaterials are sustainable sources, biodegradable, and are abundant in nature. The replacement of petrochemicals with biopolymers has gained much importance in this aspect. Conventionally, polyvinyl alcohol is employed as a protective colloid in polyvinyl acetate adhesive. Polyvinyl alcohol has the limitation of petroleum origin, is replaced by biopolymers. Starch being a biopolymer, has gained interest in replacing polyvinyl alcohol as a stabilizer. Cellulose has a low cost, and the most abundant biomaterial finds application as a reinforcing agent in conventional adhesives. Exploring cellulose as a stabilizer for polyvinyl acetate emulsion polymerization with reinforcement has created potential applicability of cellulose in adhesives. Surface hydroxyl groups in cellulose act as sites for functionalization, making it material for the adhesive sector. This review paper aims to showcase biomaterials, namely starch, and cellulose, in the adhesive field. A detailed review of cellulose as functional filler for polyvinyl acetate emulsion adhesives has been explained.
\end{abstract}

\section{Keywords}

Cellulose, Nanocellulose, Polyvinyl Acetate, Wood, Adhesive, Renewable Material

\section{Introduction}

The adhesives industry is one of the most important applications for poly (vinyl acetate) (PVAc) emulsions, especially for wood product manufacture. It has many advantages as an adhesive, e.g., low cost, ease of use, and simplicity of ap- 
plication. However, there are some inherent disadvantages of PVAc emulsions, which limit their wider usage.

Usually, the carcinogenicity of formaldehyde by its emission from conventional thermosetting resins for wood adhesives [1] [2] such as phenol-formaldehyde (PF), urea-formaldehyde (UF), and melamine-formaldehyde (MF), and considering the overexploitation of petroleum sources have accelerated scientists' in developing bio-based adhesives which are sustainable, low cost and renewable in nature [3]. Release of unreacted formaldehyde in bonded wood occurs under hot and humid conditions [4] [5]. Various biomasses have been exploited as green adhesives including cellulose [6]-[12], starch [13] [14] [15], lignin [16] [17] [18], tannin [19] [20] [21], natural rubber latex [22] [23], soy protein [24] [25] [26] and vegetable oils [27]. Researchers' acceptance of these biomaterials is due to the added advantages of renewability, eco friendliness, and very low emission of volatile organic solvents in adhesives [28] [29]. This acceptance made adhesive manufacturing industries promote green adhesives, where the low cost, easily available greener materials have been exploited even though these are in an introductory stage. Research on the partial or complete replacement of petrochemical-based raw materials in adhesives, without compensating on performance properties, provides a huge scope for commercializing bio-based adhesives [30] [31]. The importance of cellulose as a potential material to replace petrochemical-based polymer is mainly attributed to its free hydroxyls present in the cellulose structure. Moreover, being the most abundant biopolymer with biodegradability, film-forming properties, good chemical-mechanical and thermal properties, and importantly its adhesive properties can contribute to developing a better performance adhesive. Free hydroxyl groups provide the site for chemical modification which can be used for tailor-made applications [32].

\section{1) Polyvinyl alcohol stabilized polyvinyl acetate emulsion}

Water-soluble polymers have attracted coating industries and adhesive market as the demand for solvent-free adhesives increased, which have the advantage of the absence of volatile organic compounds (VOC). In this view polyvinyl alcohol (PVA) is highly important in developing organic solvent free adhesives. PVA has a controllable degree of hydrolysis $(\mathrm{DH})$ and chain length, good rheological properties with high tackiness, and affinity to porous materials made them applicable in wood consolidation purposes. Moreover, the use of PVA as a protective colloid for polyvinyl acetate (PVAc) adhesives has further created a demand for its use [33]. Emulsion polymerization of vinyl acetate to PVAc needs colloid for stability and enhances the prepared adhesive's mechanical properties, as shown in Figure 1. The degree of hydrolysis (DH), molecular weight, and molecular weight distribution of PVA are the main factors determining the colloidal stability. The general schematic representation of the aim of this review paper is shown in Figure 2. Cellulose isolated from a natural source and further modifying it by various techniques and finally incorporating with PVAc can be a technique thereby the usage of conventional PVA as a stabilizing agent for PVAc can be replaced. 


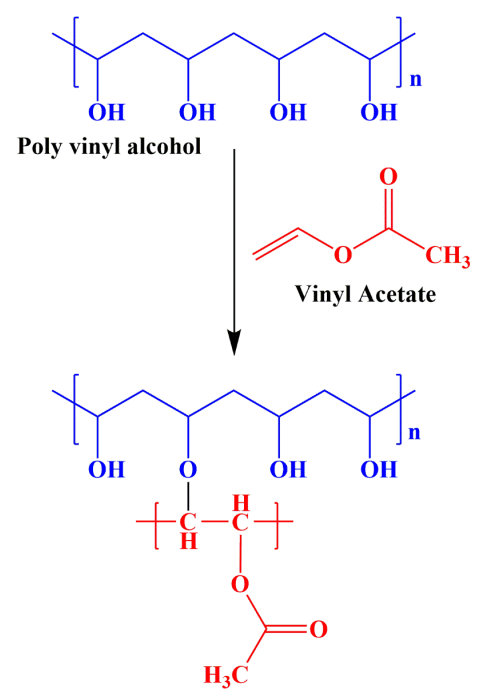

Figure 1. Stabilizing polyvinyl acetate (PVAc) with polyvinyl alcohol (PVA).

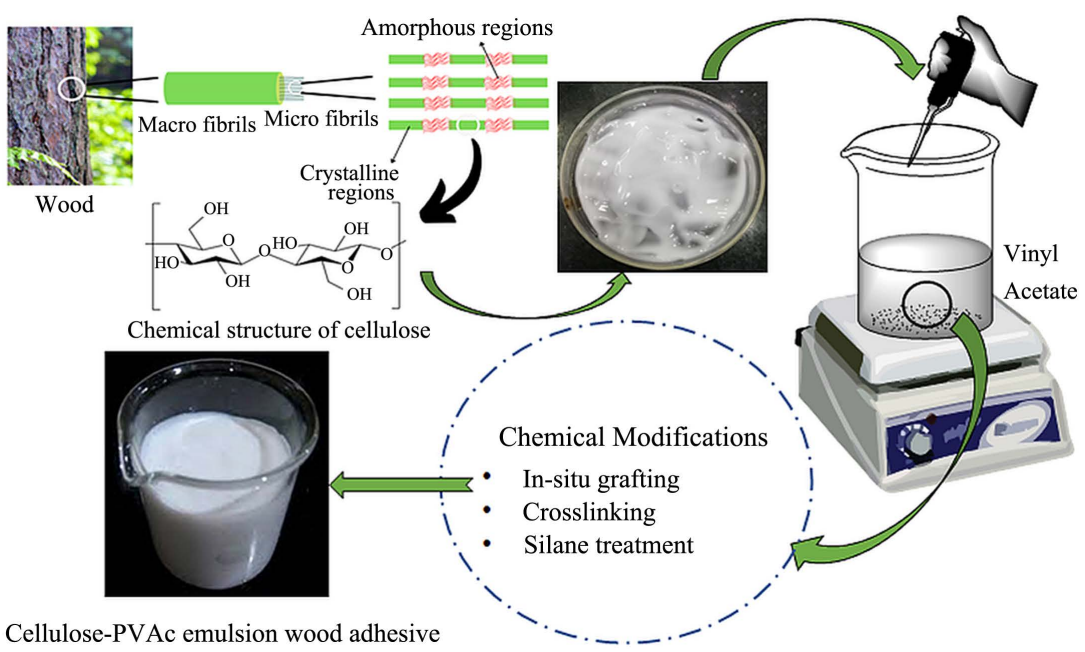

Figure 2. Schematic representation of preparing modified cellulose incorporated polyvinyl acetate (PVAc) emulsion.

Water solubility and flexibility increase when low molecular weight grade of PVA is used as protective colloid. DH affects the water solubility of the colloid because the crystallinity of fully hydrolyzed PVA needs to be heated to the boiling point of water to its complete dissolution. Whereas in partially hydrolyzed PVA, the reduction in crystallinity which is due to the presence of residual acetate groups makes it soluble in normal water [34] [35]. Modifications are done in PVA to further improving the properties [36]. Hence by tailor-making the properties, PVA act as an ideal protective colloid for PVAc emulsion-based adhesives.

However, despite all the mentioned benefits, Adding PVOH decreases adhesive water-resistance as the hydrophilic hydroxy groups are introduced into the system. Poly (vinyl acetate) is often partly hydrolyzed to form hydrophilic hydroxy groups and carboxy groups attached to the polymer backbone, usually on 
the polymer branches during emulsion polymerization. This worsens the resistance to water. The third major explanation for the weak resistance to water is that several microscopic pores and water soluble surfactant molecules in the film enable water and steam to penetrate the adhesive film quickly.

\section{2) Starch stabilized polyvinyl acetate emulsion}

The scarcity and non-renewable nature of petrochemical sources with increasing concerns on global energy crisis and investigation on alternate sources have concluded by using biomaterials in the adhesive sector. Starch, the second most abundant biomaterial obtained from nature, is inexpensive and soluble in water and has many advantages. The binding property of starch can be advantageous in adhesives [37] [38] [39], paper coating applications [40], textile applications [41], etc. Starch consists of two polysaccharide parts of glucose with different shapes and structures, amylose and amylopectin. The amount of amylose and amylopectin, shape and its size depend on the origin from where the starch is obtained. Starch has both amorphous regions and crystalline regions. The hydrogen bonding between the molecules forms a crystalline region. Lowering of reactivity in starch is resulted from the inhibition of the crystalline regions. Hence, to improve the reactivity by lowering the crystalline regions, modifications are done. Heating in water results in the disruption of crystalline regions by gelatinization, starch helices connected by the hydrogen bonds gets broken, and water penetrates to this, forming a paste [37]. Chemical modification in starch [42] includes esterification, etherification, oxidation, and crosslinking [43]. The modification can also be made by physical treatments, including ultrasonic degradation, microwave treatment, heat-moisture treatment, etc. The blending of starch with PVAc opened a new dimension of possibly or completely replacing petrochemical-based polymer, including PVA [44]. Graft polymerization of vinyl acetate monomer starch as shown in Figure 3, and its usage in wood adhesives have gained interest among researchers and industries [41] [44] [45] [46]. Improvements in thermal stability with bonding strength and water resistance are shown by graft polymerization of vinyl acetate on corn starch [47].

\section{Cellulose-Based Wood Adhesive}

Cellulose is the most abundant biopolymer, and its ability to adhere makes it an ideal biomaterial for developing green adhesives and coatings [48] [49]. It is a polysaccharide with a linear chain of glucose molecules and the repeat unit consisting of two anhydroglucose rings connected by a $\beta 1-4$ glucosidic bond. Sources of cellulose are mainly softwood and hardwood, agricultural sources such as corn, jute, and sugarcane bagasse [50] [51] [52] [53]. From these sources, cellulose is extracted, isolated, and are then modified for a specific application. Based on extraction, treatments, it can be in micro size (micro fibrillated cellulose (MFC), microcrystalline cellulose (MCC)) [54], and nano size [55] [56] [57]. Nanocellulose, classified as nanofibers (CNF), nanowhiskers, and cellulose nanocrystals (CNC), is one among the cellulosic material with one dimension in the nano range [55]. Cellulose is widely used as a reinforcing agent in various 

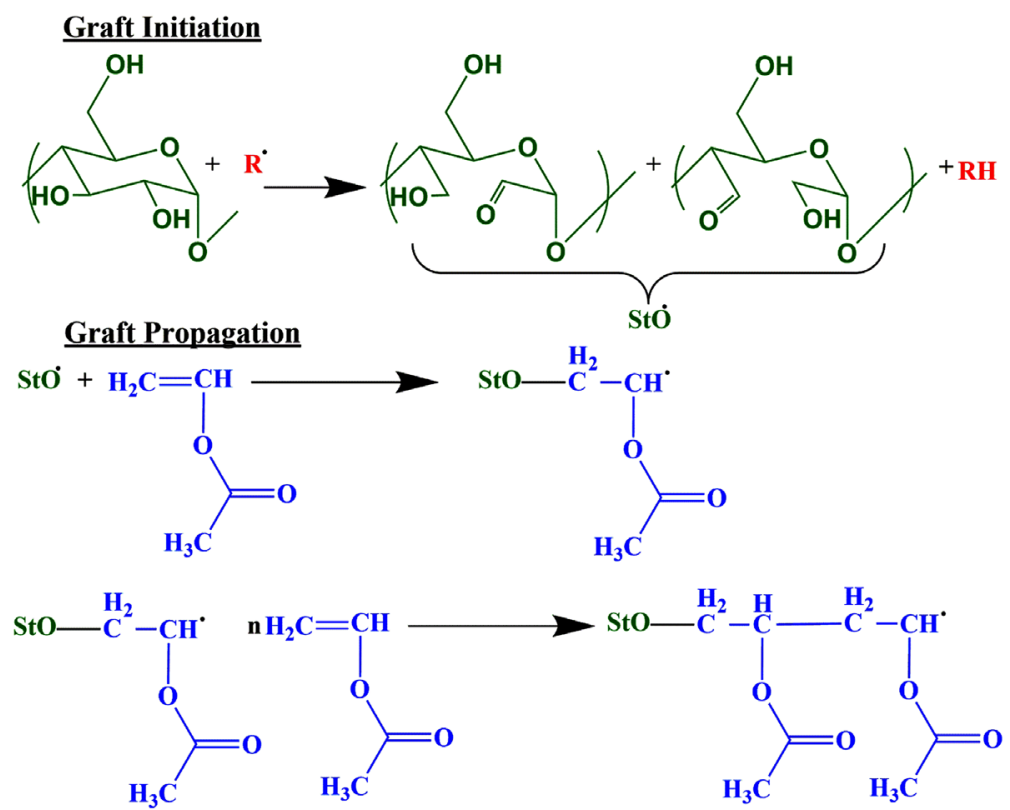

Graft Termination
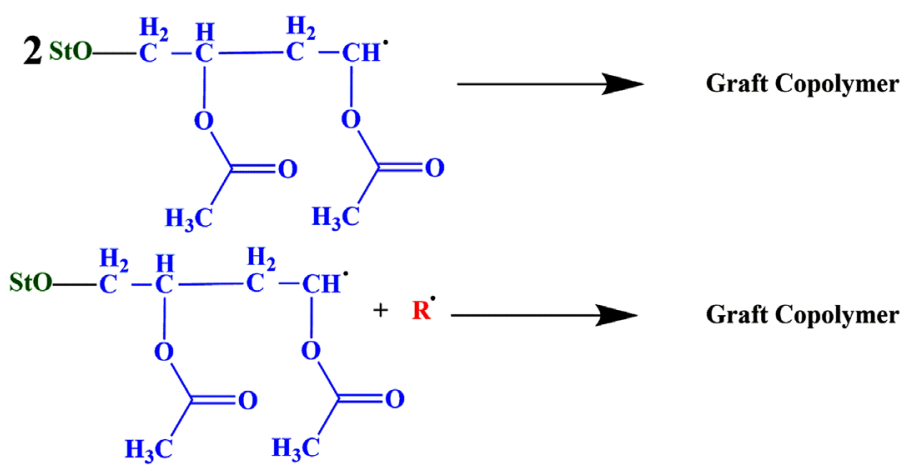

Figure 3. Mechanism of stabilized polyvinyl acetate (PVAc) using starch.

adhesive systems [58] [59] [60] [61]; Table 1 shows works regarding the base binder with the type of cellulose used and the field of application. The hydroxyl groups of cellulose make the possibility for functionalization, and hence the binding property of nanocellulose has been enhanced [3] [48] [62]. This is because nanocellulose-monomer interactions are less repulsive since monomers are smaller than polymer chains. The initial dispersion of the final composite in this sense, is improved with less agglomeration. This is especially encouraged if the polymerization process is carried out in an aqueous medium with an aqueous distribution of nanocellulose. This is perfect since the polymerization process happens in the same medium as the nanocellulose previously spread. The nanocellulose in this process is left in the water and interacts during synthesis with the exterior surface of the polymer particle [63] [64].

The added advantage of using nanocellulose in adhesives for the consolidation of wood panels include the possibility of altering the properties of adhesives, gains in physical, mechanical, and thermal properties of panels, and reduction in formaldehyde emissions by using synthetic adhesives. 
Table 1. Application of various types of cellulose used in wood joining application as adhesive.

\begin{tabular}{|c|c|c|c|c|}
\hline Sr no & Base material & Type of cellulose used & Application & Reference \\
\hline 1 & Poly(Vinyl Acetate) and Starch Adhesive & Cellulose Nanofibrils & Wood Joining & [65] \\
\hline 2 & Urea-Formaldehyde-Adhesive & Cellulose Nanofibrils & Wood Adhesive & [59] \\
\hline 3 & $\begin{array}{l}\text { Urea-Formaldehyde and Mela- } \\
\text { mine-Urea-Formaldehyde }\end{array}$ & Cellulose Nanofibers & $\begin{array}{l}\text { Particle Boards and } \\
\text { Oriented Strand Boards }\end{array}$ & [7] \\
\hline 4 & Poly(Vinyl Acetate) & Cellulose Nanofibrils & Adhesives for Wood Bonding & [66] \\
\hline 5 & Poly(Vinyl Acetate) & Nano Crystalline Cellulose & Wood Adhesive & [67] \\
\hline 6 & Tannin Adhesives & Cellulose Nanofibers & Wood Adhesives & [68] \\
\hline 7 & Urea-Formaldehyde Resin Adhesive & Modified Nanocrystalline Cellulose & Wood Adhesive & [69] \\
\hline 8 & Polyethylene Glycol & Cellulose Nano-Whiskers & Plywood Bonding & [70] \\
\hline 9 & Wood Flour & Cellulose Nanofiber & Binder in Wood Flour Board & [71] \\
\hline 10 & Wood Flour & Ligno-Cellulose Nanofibers & Wood Flour Board & [72] \\
\hline 11 & Urea-Formaldehyde & Micro fibrillated Cellulose & Laminated Veneer Lumbers & [73] \\
\hline 12 & $\begin{array}{l}\text { Sweetgum (Liquidambar Styraciflua) } \\
\quad \& \text { Southern Pine (Pinus Spp.) }\end{array}$ & Micro Crystalline Cellulose & Particle Board & [74] \\
\hline 13 & $\begin{array}{c}\text { Wood Particles } \\
\text { (80:20 Softwood: Hardwood) }\end{array}$ & Cellulose Nanofibrils & Particleboard & [75] \\
\hline 14 & Adhesive-Free Fiber-Board & Ligno Cellulose Nanofibrils & $\begin{array}{l}\text { Adhesive for Medium } \\
\text { Density Fiberboard }\end{array}$ & [76] \\
\hline 15 & Southern Pine Wood Particles & Cellulose Nanofibrils & Binder for Particleboard & [77] \\
\hline 16 & Cottonseed Protein & $\begin{array}{l}\text { Cellulose Nanofibers and } \\
\text { Cellulose Nanocrystals }\end{array}$ & Wood Adhesive & [78] \\
\hline 17 & Urea-Formaldehyde & Micro Fibrillated Cellulose & Particle Board & [10] \\
\hline 18 & Zein and Gluten Adhesive & Cellulose Nanofibers & Plywood Bonding & [79] \\
\hline 19 & Dialdehyde Cellulose & Dialdehyde Cellulose & Wood Adhesive & [80] \\
\hline 20 & Urea-Formaldehyde & Micro Fibrillated Cellulose & Wood Adhesive & [81] \\
\hline 21 & $\begin{array}{l}\text { Polymeric Diphenylmethane } \\
\text { Diisocyanate (pMDI) }\end{array}$ & Ligno-Ellulose Nanofibrils & Wood Adhesive & [82] \\
\hline 22 & Poly Vinyl Alcohol & Micro Crystalline Cellulose & Wood Adhesive & [83] \\
\hline
\end{tabular}

\section{Cellulose Stabilized Polyvinyl Acetate Emulsion}

Polyvinyl acetate (PVAc) based adhesives are mainly used in wood bonding applications due to the binding property with room temperature curing, low toxicity, chemical resistance, and biodegradability. Because of poor performance towards elevated temperatures and humid conditions limits the usage where there is a need for high performance at these conditions. Researchers have put forward two approaches to improve the performance of PVAc: 1) vinyl acetate copolymerized with monomers that are hydrophobic [84], and 2) PVAc blended with hardeners, additives, or adhesives [85] [86] [87] [88]. PVAc has the advantage of organic solvent-free adhesive with ease of processing. At the same time, the ad- 
dition of nano cellulose improves shear strength with the reduction in the size of the acrylic microsphere for pressure-sensitive adhesives [89]. Increasing content of CNF in PVAc matrix showed reinforcing effect [66] [90]. Geng et al. conducted a study in which incorporation of CNC to the crosslinked PVAc matrix by sodium tetraborate (borax) and in-situ polymerization of vinyl acetate in the presence of CNCs. Observation relating the crosslinking reaction observed to be tuned by $\mathrm{pH}$ rather than borax amount. Covalent grafting of polymers via controlled polymerizations represents another alternative route for surface modification of cellulose. Cellulose nanocrystals were successfully grafted by reversible addition-fragmentation chain transfer and macromolecular design via the interchange of xanthates polymerization (SI-RAFT/MADIX) of vinyl acetate (VAc) in a controlled manner [91]. The schematic representation of xanthates polymerization (SI-RAFT/MADIX) of vinyl acetate (VAc) is represented in Figure 4.

The in-situ nanocomposite with $10 \mathrm{wt} \%$ of CNC showed higher strength and storage modulus from thermo-mechanical analysis, and work opened the possibilities for using this material and method for green packaging and coating material applications. Kaboorani et al. observed enhancement of performance property when nanocrystalline cellulose was added to PVAc as wood adhesive [92]. With proper dispersion of nanocrystalline cellulose in the PVAc matrix, shear strength, hardness, modulus of elasticity, thermal stability and creep properties were significantly improved. The improvement of bonding strength evidenced enhancement in performance property at dry and wet conditions and the elevated temperature $\left(100^{\circ} \mathrm{C}\right)$. Chaabouni et al. investigated the effects of the addition of CNFs on the properties of waterborne PVAc adhesive [93]. An increase

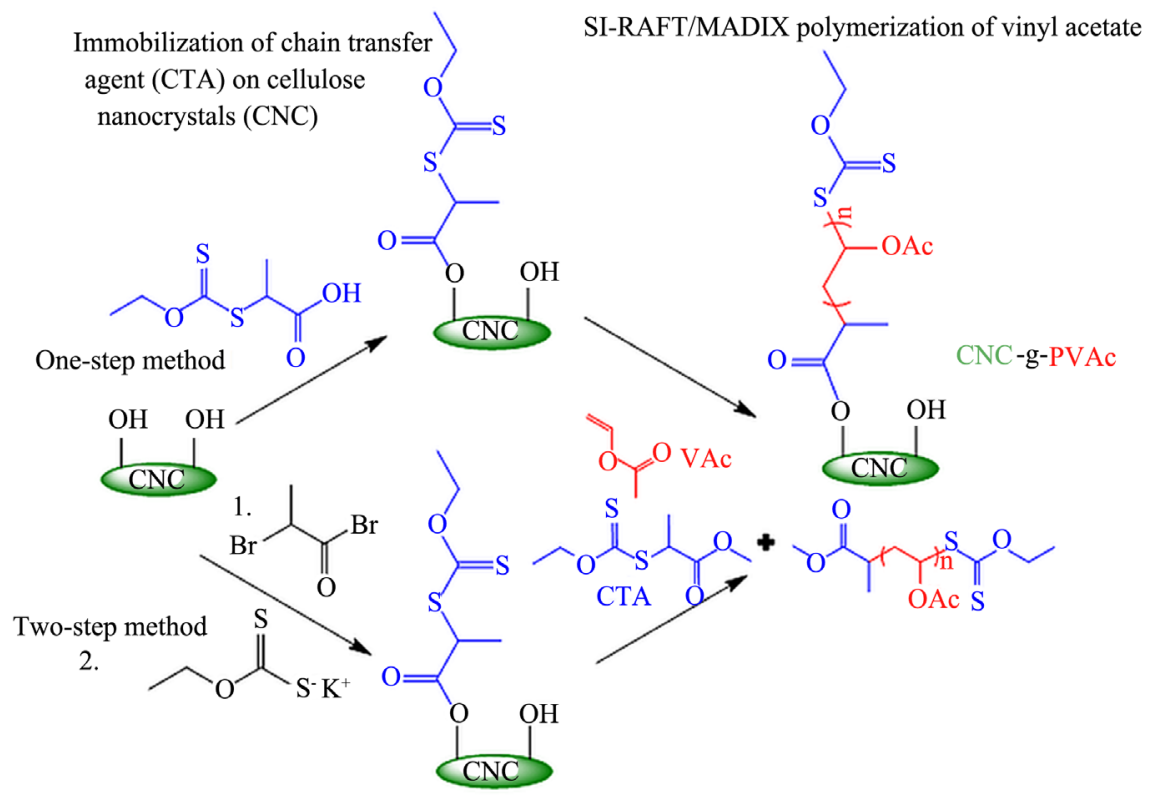

Figure 4. Schematic representation of xanthates polymerization (SI-RAFT/MADIX) of vinyl acetate (VAc) on cellulose nanocrystals (CNC). 
in viscosity was observed as the concentration of CNF increased from 0 to 10 $\mathrm{wt} \%$ while the solid content remains almost constant. Dynamic mechanical analysis (DMA) showed the reinforcing effect by CNF with the enhancement of shear strength and better cohesion of the adhesive. Improvement was shown in tensile strength, and tensile modulus of CNF filled PVAc films. A decrease in water absorption at high temperature $\left(70^{\circ} \mathrm{C}\right)$ by increasing concentration of CNF confirmed the efficiency of bonding between the filler and matrix showed good interfacial adhesion due to hydrogen bonding. A study investigated the effect of the addition of cellulose nanofibrils and nano clay on PVAc adhesive [94]. Thermal characteristics were studied, showing enhancements on incorporating fillers. Lap joint shear strength of the adhesive increased as on addition of both the filler. Morphological studies were done with scanning electron microscopy (SEM) and observed clumps for $1 \mathrm{wt} \%, 2 \mathrm{wt} \%$, and $4 \mathrm{wt} \%$. Loadings for CNFs and nano clay fillers.

In the presence of CNC, a persulfate/metabisulfite initiator was employed for in-situ emulsion polymerization of vinyl acetate without any surfactant [95]. Polyethylene glycol methacrylate (MPEG) was employed as a co-monomer and helped in the stabilization by attachment of CNC into the polymer. In the presence of MPEG, a higher reinforcing effect of CNC was observed, and films showed better transparency when the dispersion produced is in-situ, which showed potential applicability in coating and adhesives. The presence of CNC improved the shear strength of the wood joint bond, and better vales were shown in the dispersion when 5\% MPEG was present.

\section{Conclusions}

Biomaterials are among the most studied materials by the scientific world due to their renewability, non-toxicity and biodegradability. Functionalization and its ability to alter the properties have made them compete against conventional petrochemicals and hence expanded the research targeted for specific applications. PVA was initially used to stabilize PVAc emulsions. Starch provides an option to replace PVA for stabilizing PVAc. Like the structure of starch, cellulose is a member of the polysaccharide family; it is also expected to function in the same manner. Cellulose has inherent binding properties but is too weak to bond the substrates. One way to improve is by incorporation in commercial adhesives, which the researchers establish. By this method, reinforcing effects are observed and lowers the VOC emission by replacing the usage of petrochemical additives. Hence cellulose is a potential material in adhesive industry with the added advantage of renewability and biodegradability.

On the other hand, PVAc adhesives have good bonding strength, high tack, and have the advantage of formaldehyde-free and water solubility. Reinforcement of cellulose in PVAc adhesives with improvements in bonding strength and thermo-mechanical properties, and decreased water absorption have been established in the literature. Various researchers have reported the advantage of 
incorporating cellulose stabilizing the emulsion polymerization and in-situ emulsion polymerization of PVAc adhesives. Even though research and developments on cellulose-based adhesive are in their infancy, the works reported till now show the biomaterial cellulose has its applicability both as a reinforcing agent and a functional additive. Crosslinking is one such approach that can modify the cellulose as functional filler, enhancing the colloidal stability of PVAc emulsions and reduce the phase separation with filler and matrix. Hence by modifications, cellulose can be a material for stabilizing polyvinyl acetate emulsion.

\section{Futuristic Development}

The literature review established that cellulose's addition to adhesive matrix has a reinforcing effect, enhanced binding, and performance properties. The presence of hydroxyl groups provides an ideal site for functionalization, which can be an area of further research. The similarity in structure of starch and cellulose, both being polysaccharides, enables to study of the modifications in a similar way. Similar to the development of starch stabilization in PVAc, cellulose can also be employed in which research has been at the infant stage. Crosslinking can be one such way to enhance the colloidal stability of PVAc emulsions. Hence, to enhance the degree of grafting and reduce water susceptibility, cellulose will be modified, and further research will be carried.

\section{Conflicts of Interest}

The authors declare no conflicts of interest regarding the publication of this paper.

\section{References}

[1] Böhm, M., Salem, M.Z.M. and Srba, J. (2012) Formaldehyde Emission Monitoring from a Variety of Solid Wood, Plywood, Blockboard and Flooring Products Manufactured for Building and Furnishing Materials. Journal of Hazardous Materials, 221-222, 68-79. https://doi.org/10.1016/j.jhazmat.2012.04.013

[2] Arts, J.H.E., Rennen, M.A.J. and De Heer, C. (2006) Inhaled Formaldehyde: Evaluation of Sensory Irritation in Relation to Carcinogenicity. Regulatory Toxicology and Pharmacology, 44, 144-160. https://doi.org/10.1016/j.yrtph.2005.11.006

[3] Vineeth, S.K., Gadhave, R.V. and Gadekar, P.T. (2019) Nanocellulose Applications in Wood Adhesives-Review. Open Journal of Polymer Chemistry, 9, 63-75. https://doi.org/10.4236/ojpchem.2019.94006

[4] He, Z., Zhang, Y. and Wei, W. (2012) Formaldehyde and VOC Emissions at Different Manufacturing Stages of Wood-Based Panels. Building and Environment, 47, 197-204. https://doi.org/10.1016/j.buildenv.2011.07.023

[5] Roffael, E. (2006) Volatile Organic Compounds and Formaldehyde in Nature, Wood and Wood Based Panels. European Journal of Wood and Wood Products, 64, 144-149. https://doi.org/10.1007/s00107-005-0061-0

[6] Ayrilmis, N., Kwon, J.H., Lee, S.H., Han, T.H. and Park, C.W. (2016) Microfibrillated-Cellulose-Modified Urea-Formaldehyde Adhesives with Different F/U Molar 
Ratios for Wood-Based Composites. Journal of Adhesion Science and Technology, 30, 2032-2043. https://doi.org/10.1080/01694243.2016.1175246

[7] Veigel, S., Rathke, J., Weigl, M. and Gindl-Altmutter, W. (2012) Particle Board and Oriented Strand Board Prepared with Nanocellulose-Reinforced Adhesive. Journal of Nanomaterials, 2012, Article ID: 158503. https://doi.org/10.1155/2012/158503

[8] Vineeth, S.K., Gadhave, R.V. and Gadekar, P.T. (2019) Chemical Modification of Nanocellulose in Wood Adhesive: Review. Open Journal of Polymer Chemistry, 9, 86-99. https://doi.org/10.4236/ojpchem.2019.94008

[9] Hamed, S.A.A.K.M. and Hassan, M.L. (2019) A New Mixture of Hydroxypropyl Cellulose and Nanocellulose for Wood Consolidation. Journal of Cultural Heritage, 35, 140-144. https://doi.org/10.1016/j.culher.2018.07.001

[10] Mahrdt, E., Pinkl, S., Schmidberger, C., van Herwijnen, H.W.G., Veigel, S. and Gindl-Altmutter, W. (2016) Effect of Addition of Microfibrillated Cellulose to Urea-Formaldehyde on Selected Adhesive Characteristics and Distribution in Particle Board. Cellulose, 23, 571-580. https://doi.org/10.1007/s10570-015-0818-5

[11] Hon, D.N.-S. (1989) Cellulosic Adhesives. In: Richard, S.J.B., Hemingway, W. and Conner, A.H., Eds., Adhesives from Renewable Resources, ACS Symposium Series, American Chemical Society, Washington DC, 289-304. https://doi.org/10.1021/bk-1989-0385.ch021

[12] Zhang, X.J. (2000) Adhesion Properties of Cellulose Films. MRS. Online Proceeding Library Archive, 586, 1-29. https://doi.org/10.1557/PROC-586-157

[13] Gadhave, R.V., Mahanwar, P.A. and Gadekar, P.T. (2019) Study on Various Compositions of Polyvinyl Alcohol and Starch Blends by Crosslinking with Glyoxal. Open Journal of Polymer Chemistry, 9, 76-85. https://doi.org/10.4236/ojpchem.2019.94007

[14] Wang, Z., Li, Z., Gu, Z., Hong, Y. and Cheng, L. (2012) Preparation, Characterization and Properties of Starch-Based Wood Adhesive. Carbohydrate Polymers, 88, 699-706. https://doi.org/10.1016/j.carbpol.2012.01.023

[15] Wang, Z., et al. (2019) Improvement of the Bonding Properties of Cassava Starch-Based Wood Adhesives by Using Different Types of Acrylic Ester. International Journal of Biological Macromolecules, 126, 603-611. https://doi.org/10.1016/j.ijbiomac.2018.12.113

[16] Kalami, S., Chen, N., Borazjani, H. and Nejad, M. (2018) Comparative Analysis of Different Lignins as Phenol Replacement in Phenolic Adhesive Formulations. Industrial Crops and Products, 125, 520-528. https://doi.org/10.1016/j.indcrop.2018.09.037

[17] Yang, Z., Peng, H., Wang, W. and Liu, T. (2010) Lignin-Based Polycondensation Resins for Wood Adhesives. Journal of Applied Polymer Science, 116, 2658-2667.

[18] Moubarik, A., Grimi, N., Boussetta, N. and Pizzi, A. (2013) Isolation and Characterization of Lignin from Moroccan Sugar Cane Bagasse: Production of Lignin-PhenolFormaldehyde Wood Adhesive. Industrial Crops and Products, 45, 296-302. https://doi.org/10.1016/j.indcrop.2012.12.040

[19] Moubarik, A., Allal, A., Pizzi, A., Charrier, F. and Charrier, B. (2010) Characterization of a Formaldehyde-Free Cornstarch-Tannin Wood Adhesive for Interior Plywood. European Journal of Wood and Wood Products, 68, 427-433. https://doi.org/10.1007/s00107-009-0379-0

[20] Navarrete, P., et al. (2012) Low Formaldehyde Emitting Biobased Wood Adhesives Manufactured from Mixtures of Tannin and Glyoxylated Lignin. Journal of Adhesion Science and Technology, 26, 1667-1684. 
https://doi.org/10.1163/156856111X618489

[21] Gadhave, R.V., Dhawale, P.V. and Gadekar, P.T. (2020) Effect of Boric Acid on Poly Vinyl Alcohol-Tannin Blend and Its Application as Water-Based Wood Adhesive. Designed Monomers and Polymers, 23, 188-196.

https://doi.org/10.1080/15685551.2020.1826124

[22] John, N. and Joseph, R. (1997) Studies on Wood-to-Wood Bonding Adhesives Based on Natural Rubber Latex. Journal of Adhesion Science and Technology, 11, 225-232. https://doi.org/10.1163/156856197X00327

[23] Thuraisingam, J., Mishra, P., Gupta, A., Soubam, T. and Piah, B.M. (2019) Novel Natural Rubber Latex/Lignin-Based Bio-Adhesive: Synthesis and Its Application on Medium Density Fiber-Board. Iranian Polymer Journal, 28, 283-290. https://doi.org/10.1007/s13726-019-00696-5

[24] Luo, J., Luo, J., Bai, Y., Gao, Q. and Li, J. (2016) A High Performance Soy Protein-Based Bio-Adhesive Enhanced with a Melamine/Epichlorohydrin Prepolymer and Its Application on Plywood. RSC Advances, 6, 67669-67676.

https://doi.org/10.1039/C6RA15597A

[25] Vnučec, D., Kutnar, A. and Goršek, A. (2017) Soy-Based Adhesives for WoodBonding-A Review. Journal of Adhesion Science and Technology, 31, 910-931. https://doi.org/10.1080/01694243.2016.1237278

[26] Lei, H., Du, G., Wu, Z., Xi, X. and Dong, Z. (2014) Crosslinked Soy-Based Wood Adhesives for Plywood. International Journal of Adhesion and Adhesives, 50, 199-203. https://doi.org/10.1016/j.ijadhadh.2014.01.026

[27] Sulaiman, N.S., Hashim, R., Sulaiman, O., Nasir, M., Amini, M.H.M. and Hiziroglu, S. (2018) Partial Replacement of Urea-Formaldehyde with Modified Oil Palm Starch Based Adhesive to Fabricate Particleboard. International Journal of Adhesion and Adhesives, 84, 1-8. https://doi.org/10.1016/j.ijadhadh.2018.02.002

[28] Jang, Y., Huang, J. and Li, K. (2011) A New Formaldehyde-Free Wood Adhesive from Renewable Materials. International Journal of Adhesion and Adhesives, 31, 754-759. https://doi.org/10.1016/j.ijadhadh.2011.07.003

[29] Prasittisopin, L. and Li, K. (2010) A New Method of Making Particleboard with a Formaldehyde-Free Soy-Based Adhesive. Composites Part A: Applied Science and Manufacturing, 41, 1447-1453. https://doi.org/10.1016/j.compositesa.2010.06.006

[30] Pizzi, A. (2006) Recent Developments in Eco-Efficient Bio-Based Adhesives for Wood Bonding: Opportunities and Issues. Journal of Adhesion Science and Technology, 20, 829-846. https://doi.org/10.1163/156856106777638635

[31] Heinrich, L.A. (2019) Future Opportunities for Bio-Based Adhesives-Advantages beyond Renewability. Green Chemistry, 21, 1866-1888.

https://doi.org/10.1039/C8GC03746A

[32] Vineeth, S.K., Gadhave, R.V. and Gadekar, P.T. (2020) Glyoxal Cross-Linked Polyvinyl Alcohol-Microcrystalline Cellulose Blend as a Wood Adhesive with Enhanced Mechanical, Thermal and Performance Properties. Materials International, 2, 277285.

[33] Gonzalez, G.S.M., Dimonie, V.L., Sudol, E.D., Yue, H.J., Klein, A. and El-Aasser, M.S. (1996) Characterization of Poly(vinyl alcohol) during the Emulsion Polymerization of Vinyl Acetate Using Poly(vinyl alcohol) as Emulsifier. Journal of Polymer Science Part A: Polymer Chemistry, 34, 849-862.

https://doi.org/10.1002/(SICI)1099-0518(19960415)34:5<849::AID-POLA14>3.0.C $\underline{\mathrm{O} ; 2-\mathrm{I}}$

[34] Nakamae, M., Yuki, K., Sato, T. and Maruyama, H. (1999) Preparation of Polymer 
Emulsions Using a Poly(vinyl alcohol) as Protective Colloid. Colloids and Surfaces A: Physicochemical and Engineering Aspects, 153, 367-372. https://doi.org/10.1016/S0927-7757(98)00458-0

[35] Qiao, L., Coveny, P.K. and Easteal, A.J. (2002) Modifications of Poly(vinyl alcohol) for Use in Poly(vinyl acetate) Emulsion Wood Adhesives. Pigment \& Resin Technology, 31, 88-95. https://doi.org/10.1108/03699420210420378

[36] Mori, A., Kitayama, T., Takatani, M. and Okamoto, T. (2004) A Honeymoon-Type Adhesive for Wood Products Based on Acetoacetylated Poly(vinyl alcohol) and Diamines: Effect of Diamines and Degree of Acetoacetylation. Journal of Applied Polymer Science, 91, 2966-2972. https://doi.org/10.1002/app.13491

[37] D’Amico, S., Hrabalova, M., Müller, U. and Berghofer, E. (2010) Bonding of Spruce Wood with Wheat Flour Glue-Effect of Press Temperature on the Adhesive Bond Strength. Industrial Crops and Products, 31, 255-260. https://doi.org/10.1016/j.indcrop.2009.11.001

[38] Gadhave, R.V., Vineeth, S.K. and Gadekar, P.T. (2020) Crosslinking of Polyvinyl Alcohol/Starch Blends by Glutaraldehyde Sodium Bisulfite for Improvement in Thermal and Mechanical Properties. Journal of Materials and Environmental Science, 11, 704-712.

[39] Vineeth, S.K., Gadhave, R.V. and Gadekar, P.T. (2021) Investigation of Crosslinking Ability of Sodium Metabisulphite with Polyvinyl Alcohol-Corn Starch Blend and Its Applicability as Wood Adhesive. Indian Chemical Engineer. https://doi.org/10.1080/00194506.2021.1887769

[40] Li, H., Qi, Y., Zhao, Y., Chi, J. and Cheng, S. (2019) Starch and Its Derivatives for Paper Coatings: A Review. Progress in Organic Coatings, 135, 213-227. https://doi.org/10.1016/j.porgcoat.2019.05.015

[41] Meshram, M.W., Patil, V.V., Mhaske, S.T. and Thorat, B.N. (2009) Graft Copolymers of Starch and Its Application in Textiles. Carbohydrate Polymers, 75, 71-78. https://doi.org/10.1016/j.carbpol.2008.06.012

[42] Zhang, Z., Macquarrie, D.J., Clark, J.H. and Matharu, A.S. (2014) Chemical Modification of Starch and the Application of Expanded Starch and Its Esters in Hot Melt Adhesive. RSC Advances, 4, 41947-41955. https://doi.org/10.1039/C4RA08027K

[43] Yin, Y., Li, J., Liu, Y. and Li, Z. (2005) Starch Crosslinked with Poly(vinyl alcohol) by Boric Acid. Journal of Applied Polymer Science, 96, 1394-1397. https://doi.org/10.1002/app.21569

[44] Samaha, S.H., Nasr, H.E. and Hebeish, A. (2005) Synthesis and Characterization of Starch-Poly(vinyl Acetate) Graft Copolymers and Their Saponified Form. Journal of Polymer Research, 12, 343-353. https://doi.org/10.1007/s10965-004-7937-2

[45] Lai, S.M., Don, T.M., Liu, Y.H. and Chiu, W.Y. (2006) Graft Polymerization of Vinyl Acetate onto Granular Starch: Comparison on the Potassium Persulfate and Ceric Ammonium Nitrate Initiated System. Journal of Applied Polymer Science, 102, 3017-3027. https://doi.org/10.1002/app.24672

[46] Gadhave, R.V., Mahanwar, P.A. and Gadekar, P.T. (2018) Starch Stabilized Polyvinyl Acetate Emulsion: Review. Polymers from Renewable Resources, 9, 75-84. https://doi.org/10.1177/204124791800900203

[47] Wang, Z., Gu, Z., Li, Z., Hong, Y. and Cheng, L. (2013) Effects of Emulsifier on the Bonding Performance and Freeze-Thaw Stability of Starch-Based Wood Adhesive. Cellulose, 20, 2583-2590. https://doi.org/10.1007/s10570-013-9984-5

[48] Tayeb, A.H., Amini, E., Ghasemi, S. and Tajvidi, M. (2018) Cellulose Nanomate- 
rials-Binding Properties and Applications: A Review. Molecules, 23, 1-24. https://doi.org/10.3390/molecules23102684

[49] Grüneberger, F., Künniger, T., Zimmermann, T. and Arnold, M. (2014) Nanofibrillated Cellulose in Wood Coatings: Mechanical Properties of Free Composite Films. Journal of Materials Science, 49, 6437-6448.

https://doi.org/10.1007/s10853-014-8373-2

[50] Singh, H.K., Patil, T., Vineeth, S.K., Das, S., Pramanik, A. and Mhaske, S.T. (2019) Isolation of Microcrystalline Cellulose from Corn Stover with Emphasis on Its Constituents: Corn Cover and Corn Cob. Materials Today: Proceedings, 5, 8299-8306. https://doi.org/10.1016/j.matpr.2019.12.065

[51] Davoudpour, Y., et al. (2015) Optimization of High Pressure Homogenization Parameters for the Isolation of Cellulosic Nanofibers Using Response Surface Methodology. Industrial Crops and Products, 74, 381-387.

https://doi.org/10.1016/j.indcrop.2015.05.029

[52] Lamaming, J., Hashim, R., Sulaiman, O., Leh, C.P., Sugimoto, T. and Nordin, N.A. (2015) Cellulose Nanocrystals Isolated from Oil Palm Trunk. Carbohydrate Polymers, 127, 202-208. https://doi.org/10.1016/j.carbpol.2015.03.043

[53] Candido, R.G. and Gonçalves, A.R. (2019). Evaluation of Two Different Applications for Cellulose Isolated from Sugarcane Bagasse in a Biorefinery Concept. Industrial Crops and Products, 142, Article ID: 111616. https://doi.org/10.1016/j.indcrop.2019.111616

[54] Ferreira, F.V., Mariano, M., Rabelo, S.C., Gouveia, R.F. and Lona, L.M.F. (2018) Isolation and Surface Modification of Cellulose Nanocrystals from Sugarcane Bagasse Waste: From a Micro- to a Nano-Scale View. Applied Surface Science, 436, 1113-1122. https://doi.org/10.1016/j.apsusc.2017.12.137

[55] Moon, R.J., Martini, A., Nairn, J., Simonsen, J. and Youngblood, J. (2011) Cellulose Nanomaterials Review: Structure, Properties and Nanocomposites. Chemical Society Reviews, 40, 3941-3994. https://doi.org/10.1039/c0cs00108b

[56] George, J. and Sabapathi, S.N. (2015) Cellulose Nanocrystals: Synthesis, Functional Properties, and Applications. Nanotechnology, Science and Applications, 8, 45-54. https://doi.org/10.2147/NSA.S64386

[57] Mondal, S. (2017) Preparation, Properties and Applications of Nanocellulosic Materials. Carbohydrate Polymers, 163, 301-316.

https://doi.org/10.1016/j.carbpol.2016.12.050

[58] Dastjerdi, Z., Cranston, E.D. and Dubé, M.A. (2018) Pressure Sensitive Adhesive Property Modification Using Cellulose Nanocrystals. International Journal of Adhesion and Adhesives, 81, 36-42. https://doi.org/10.1016/j.ijadhadh.2017.11.009

[59] Veigel, S., Müller, U., Keckes, J., Obersriebnig, M. and Gindl-Altmutter, W. (2011) Cellulose Nanofibrils as Filler for Adhesives: Effect on Specific Fracture Energy of Solid Wood-Adhesive Bonds. Cellulose, 18, 1227-1237. https://doi.org/10.1007/s10570-011-9576-1

[60] Gindl-Altmutter, W. and Veigel, S. (2014) Nanocellulose-Modified Wood Adhesives. In: Oksman, K., Mathew, A.P., Bismarck, A., Rojas, O. and Sain, M., Eds., Handbook of Green Materials. Bionanomaterials: Separation Processes, Characterization and Properties, World Scientific Publishing, Singapore, 253-264. https://doi.org/10.1142/9789814566469 0031

[61] Cataldi, A., Berglund, L., Deflorian, F. and Pegoretti, A. (2015) A Comparison between Micro- and Nanocellulose-Filled Composite Adhesives for Oil Paintings Restoration. Nanocomposites, 1, 195-203. 
https://doi.org/10.1080/20550324.2015.1117239

[62] Tajvidi, M., Gardner, D.J. and Bousfield, D.W. (2016) Cellulose Nanomaterials as Binders: Laminate and Particulate Systems. Journal of Renewable Materials, 4, 365-376. https://doi.org/10.7569/JRM.2016.634103

[63] Tang, J., Lee, M.F.X., Zhang, W., Zhao, B., Berry, R.M. and Tam, K.C. (2014) Dual Responsive Pickering Emulsion Stabilized by Poly[2-(dimethylamino) ethyl methacrylate] Grafted Cellulose Nanocrystals. Biomacromolecules, 15, 3052-3060. https://doi.org/10.1021/bm500663w

[64] Hu, Z., Ballinger, S., Pelton, R. and Cranston, E.D. (2015) Surfactant-Enhanced Cellulose Nanocrystal Pickering Emulsions. Journal of Colloid and Interface Science, 439, 139-148. https://doi.org/10.1016/j.jcis.2014.10.034

[65] Jiang, W., et al. (2018) Effect of Cellulose Nanofibrils on the Bond Strength of Polyvinyl Acetate and Starch Adhesives for Wood. BioResources, 13, 2283-2292. https://doi.org/10.15376/biores.13.2.2283-2292

[66] López-Suevos, F., Eyholzer, C., Bordeanu, N. and Richter, K. (2010) DMA Analysis and Wood Bonding of PVAc Latex Reinforced with Cellulose Nanofibrils. Cellulose, 17, 387-398. https://doi.org/10.1007/s10570-010-9396-8

[67] Pakdel, A.S., Gabriel, V., Berry, R.M., et al. (2020) A Sequential Design Approach for in Situ Incorporation of Cellulose Nanocrystals in Emulsion-Based Pressure Sensitive Adhesives. Cellulose, 27, 10837-10853. https://doi.org/10.1007/s10570-020-03060-6

[68] Cui, J., et al. (2015) Enhancement of Mechanical Strength of Particleboard Using Environmentally Friendly Pine (Pinus pinaster L.) Tannin Adhesives with Cellulose Nanofibers. Annals of Forest Science, 72, 27-32. https://doi.org/10.1007/s13595-014-0392-2

[69] Pu, J.W., Zhang, H., Zhang, J., Song, S.P. and Wu, G.F. (2011) Modified Nanocrystalline Cellulose from Two Kinds Emission and Bonding Strength of Urea-Fromaldehyde Resin Adhesive. BioResources, 6, 4430-4438.

[70] Gao, Q., Li, J., Shi, S.Q., Liang, K. and Zhang, X. (2012) Soybean Meal-Based Adhesive Reinforced with Cellulose Nanowhiskers. BioResources, 7, 5622-5633.

https://doi.org/10.15376/biores.7.4.5622-5633

[71] Kojima, Y., et al. (2013) Binding Effect of Cellulose Nanofibers in Wood Flour Board. Journal of Wood Science, 59, 396-401. https://doi.org/10.1007/s10086-013-1348-0

[72] Kojima, Y., et al. (2014) Evaluation of Binding Effects in Wood Flour Board Containing Ligno-Cellulose Nanofibers. Materials (Basel), 6, 6853-6864.

https://doi.org/10.3390/ma7096853

[73] Ayrilmis, N., Lee, Y.K., Kwon, J.H., Han, T.H. and Kim, H.J. (2016) Formaldehyde Emission and VOCs from LVLs Produced with Three Grades of Urea-Formaldehyde Resin Modified with Nanocellulose. Building and Environment, 97, 82-87. https://doi.org/10.1016/j.buildenv.2015.12.009

[74] Atta-Obeng, E., Via, B.K. and Fasina, O. (2012) Effect of Microcrystalline Cellulose, Species, and Particle Size on Mechanical and Physical Properties of Particleboard. Wood and Fiber Science, 44, 227-235.

[75] Hunt, J.F., Leng, W. and Tajvidi, M. (2017) Vertical Density Profile and Internal Bond Strength of Wet-Formed Particleboard Bonded with Cellulose Nanofibrils. Wood and Fiber Science, 49, 413-423.

[76] Diop, C.I.K., Tajvidi, M., Bilodeau, M.A., Bousfield, D.W. and Hunt, J.F. (2017) 
Evaluation of the Incorporation of Lignocellulose Nanofibrils as Sustainable Adhesive Replacement in Medium Density Fiberboards. Industrial Crops and Products, 109, 27-36. https://doi.org/10.1016/j.indcrop.2017.08.004

[77] Amini, E., Tajvidi, M., Gardner, D.J. and Bousfield, D.W. (2017) Utilization of Cellulose Nanofibrils as a Binder for Particleboard Manufacture. BioResources, 12, 4093-4110. https://doi.org/10.15376/biores.12.2.4093-4110

[78] Cheng, H.N., Kilgore, K., Ford, C., Fortier, C., Dowd, M.K. and He, Z. (2019) Cottonseed Protein-Based Wood Adhesive Reinforced with Nanocellulose. Journal of Adhesion Science and Technology, 33, 1357-1368. https://doi.org/10.1080/01694243.2019.1596650

[79] Oh, M., Ma, Q., Simsek, S., Bajwa, D. and Jiang, L. (2019) Comparative Study of Zein- and Gluten-Based Wood Adhesives Containing Cellulose Nano Fibers and Crosslinking Agent for Improved Bond Strength. International Journal of Adhesion and Adhesives, 92, 44-57. https://doi.org/10.1016/j.ijadhadh.2019.04.004

[80] Zhang, H., Liu, P., Musa, S., Mai, C. and Zhang, K. (2019) Dialdehyde Cellulose as a Bio-Based Robust Adhesive for Wood Bonding. ACS Sustainable Chemistry \& Engineering, 7, 10452-10459. https://doi.org/10.1021/acssuschemeng.9b00801

[81] Kwon, J.H., Lee, S., Ayrilmis, H. and Hyung, N.T. (2015) Tensile Shear Strength of Wood Bonded with Urea-Formaldehyde with Different Amounts of Microfibrillated Cellulose. International Journal of Adhesion and Adhesives, 60, 88-91.

[82] Chen, H., Nair, S.S., Chauhan, P. and Yan, N. (2019) Lignin Containing Cellulose Nanofibril Application in pMDI Wood Adhesives for Drastically Improved Gap-Filling Properties with Robust Bondline Interfaces. Chemical Engineering Journal, 360, 393-401. https://doi.org/10.1016/j.cej.2018.11.222

[83] Gadhave, R.V., Vineeth, S.K., Mahanwar, P.A. and Pradeep, T. (2020) Effect of Addition of Boric Acid on Thermo-Mechanical Properties of Microcrystalline Cellulose/Polyvinyl Alcohol Blend and Applicability as Wood Adhesive. Journal of Adhesion Science and Technology, 1-15.

[84] Zhang, Y., et al. (2018) Improvement in Wood Bonding Strength of Poly(vinyl acetate-butyl acrylate) Emulsion by Controlling the Amount of Redox Initiator. Materials (Basel), 11, 89. https://doi.org/10.3390/ma11010089

[85] Kaboorani, A. and Riedl, B. (2011) Improving Performance of Polyvinyl Acetate (PVA) as a Binder for Wood by Combination with Melamine Based Adhesives. In ternational Journal of Adhesion and Adhesives, 31, 605-611. https://doi.org/10.1016/j.ijadhadh.2011.06.007

[86] Kim, S. and Kim, H.J. (2005) Effect of Addition of Polyvinyl Acetate to Melamine-Formaldehyde Resin on the Adhesion and Formaldehyde Emission in Engineered Flooring. International Journal of Adhesion and Adhesives, 25, 456-461. https://doi.org/10.1016/j.ijadhadh.2005.01.001

[87] López-Suevos, F. and Frazier, C.E. (2006) Fracture Cleavage Analysis of PVAc Latex Adhesives: Influence of Phenolic Additives. Holzforschung, 60, 313-317. https://doi.org/10.1515/HF.2006.050

[88] Khan, U., May, P., Porwal, H., Nawaz, K. and Coleman, J.N. (2013) Improved Adhesive Strength and Toughness of Polyvinyl Acetate Glue on Addition of Small Quantities of Graphene. ACS Applied Materials \& Interfaces, 5, 1423-1428. https://doi.org/10.1021/am302864f

[89] Kajtna, J. and Šebenik, U. (2017) Novel Acrylic/Nanocellulose Microsphere with Improved Adhesive Properties. International Journal of Adhesion and Adhesives, 74, 100-106. https://doi.org/10.1016/j.ijadhadh.2016.11.013 
[90] Gong, G., Pyo, J., Mathew, A.P. and Oksman, K. (2011) Tensile Behavior, Morphology and Viscoelastic Analysis of Cellulose Nanofiber-Reinforced (CNF) Polyvinyl Acetate (PVAc). Composites Part A, 42, 1275-1282.

https://doi.org/10.1016/j.compositesa.2011.05.009

[91] Geng, S., Haque, M. and Oksman, K. (2016) Crosslinked Poly(vinyl acetate) (PVAc) Reinforced with Cellulose Nanocrystals (CNC): Structure and Mechanical Properties. Composites Science and Technology, 126, 35-42.

https://doi.org/10.1016/j.compscitech.2016.02.013

[92] Kaboorani, A., Riedl, B., Blanchet, P., Fellin, M., Hosseinaei, O. and Wang, S. (2012) Nanocrystalline Cellulose (NCC): A Renewable Nano-Material for Polyvinyl Acetate (PVA) Adhesive. European Polymer Journal, 48, 1829-1837.

https://doi.org/10.1016/j.eurpolymj.2012.08.008

[93] Chaabouni, O. and Boufi, S. (2017) Cellulose Nanofibrils/Polyvinyl Acetate Nanocomposite Adhesives with Improved Mechanical Properties. Carbohydrate Polymers, 156, 64-70. https://doi.org/10.1016/j.carbpol.2016.09.016

[94] Aydemir, D., Gündüz, G., Aşik, N. and Wang, A. (2016) The Effects of Poly(vinylacetate) Filled with Nanoclay and Cellulose Nanofibrils on Adhesion Strength of Poplar and Scots Pine Wood. Drvna Industrija, 67, 17-24.

https://doi.org/10.5552/drind.2016.1441

[95] Boufi, S., Mabrouk, A.B. and Dufresne, A. (2019) Cellulose Nanocrystal as Ecofriendly Stabilizer for Emulsion Polymerization and Its Application for Waterborne Adhesive. Carbohydrate Polymers, 229, Article ID: 115504.

https://doi.org/10.1016/j.carbpol.2019.115504 